\title{
Decoupled Feed Forward Voltage Oriented Controller for DFIG under Balanced and Unbalanced Fault Conditions
}

\author{
Dileep Kumar Varma* ${ }^{*^{1}}$, Y. P. Obulesh ${ }^{2}$, Ch. Sai Babu ${ }^{3}$ \\ ${ }^{1}$ Department of Electrical and Electronics Engineering, Shri Vishnu Engineering College for Women, \\ Bhimavaram, India, \\ ${ }^{2}$ Department of Electrical and Electronics Engineering, K.L.University, \\ Vaddeswaram, Guntur District, India, \\ ${ }^{3}$ Department of Electrical and Electronics Engineering, JNTUK \\ Kakinada, India, \\ *Corresponding author, e-mail: varma8332@gmail.com ${ }^{1}$, ypobulesh@gmail.com² ${ }^{2}$ chs_eee@yahoo.co.in ${ }^{3}$
}

\begin{abstract}
As Wind Power Penetration increases continuously in total Power Generation, the wind turbines are necessary to stay connected to grid even under grid disturbances. An enhanced control strategy for DFIG is proposed in the present paper to meet the latest grid codes set by grid operators. The Decoupled Current Controller implemented in Grid Voltage oriented reference frame is applied to Grid Side Converter (GSC) to improve the dynamic performance of DFIG. The Proposed scheme enhances the Low Voltage ride through capability of Wind farm by providing reactive Power support under adverse grid conditions. The Proposed scheme also counteracts the ripples in DC Link voltage, stator/rotor currents and stator/reactive power to fulfill the grid code commitments in weak grid.Simulation results are presented to verify the feasibility and robustness of the proposed control scheme.
\end{abstract}

Keywords: double fed induction generator (DFIG), grid side converter (GSC), low voltage ride through capability ( $L V R T)$, fault ride through capability (FRT)

Copyright $(2015$ Institute of Advanced Engineering and Science. All rights reserved.

\section{Introduction}

Today Power demand is escalating in a rapid manner due to various reasons such as environmental and economic problems. The DFIG wind farms have become more popular and received more attention due to its various advantages like better variable speed control, more economical, good wind power control, better Voltage and frequency support when connected to power grid [1-2]. Today Wind Power progress is rising extensively for the past few decades all over the world. This rapid increase in Wind Generation makes the grid Operators to impose stringent Grid codes for Wind Power Generators for voltage support and uninterrupted Power Supply [3-4]. According to Indian Electricity Grid codes IEGC [5], Wind farms must remain connected to grid even under fault Conditions for a specific period of time approximately for about 300ms. The LVRT Capability curve for Grid connected Wind farm is shown in Figure (2), Where Vf represents $15 \%$ of the nominal System Voltage below which the wind turbine will be disconnected. The important feature of DFIG is that the machine side and grid side converters are only $30 \%$ of the generator rating resulting in less cost. As DFIG stator is directly connected to power grid, so any disturbances in the grid will result in increase in voltage at Wind farm and at Point of interconnection and produces Stator dc Flux component. This stator dc flux component results large transient voltage and current in the machine side converter which damages the DFIG converters and results in wind turbine to disconnect from service [6-7]. To avoid LVRT Problem in DFIG System, Crowbar Circuit at RSC for Protecting DFIG Converters under abnormal conditions is reported in [8]. But when Crowbar circuit is activated rotor side converter gets blocked and the wind Generator acts as squirrel cage induction machine drawing large reactive Power which further lowers the voltage at the wind farm leads to tripping of wind turbine. But new grid codes are not allowing to trip the wind turbines under abnormal conditions. Another Solution to LVRT is using Energy storage system connected across dc terminals to 
balance the Power flow to dc link capacitor to avoid the the over voltage across dc link capacitor is documented in [9]. The Chopper Circuit with resistor is usually connected across dc link to smooth out the dc link variations under abnormal conditions are reported in [10-11]. From the principle of normal crowbar protection scheme some more enhanced crowbar protection schemes have also been well documented in the literature to improve DFIG LVRT requirements [12-13]. But the above mentioned proposed schemes have certain limitations due to extra cost involved in hardware design of crowbar circuit and braking resistors. A robust current controller is required for grid side converter to avoid tripping of wind turbine when the rotor side converter is disabled under abnormal conditions. As reported in [13], the VOC Control scheme uses PI controller for tracking desired current into grid but tracking performance is not fair due to coupling terms involved in this control strategy. To improve tracking performance, dynamic response and to enhance the LVRT and FRT Capability a decoupled Voltage Oriented current controller with Feed forward Compensation is presented in this Paper. This Paper is formulated as shown below. Section 2 addresses mathematical modeling of Grid side Converter.

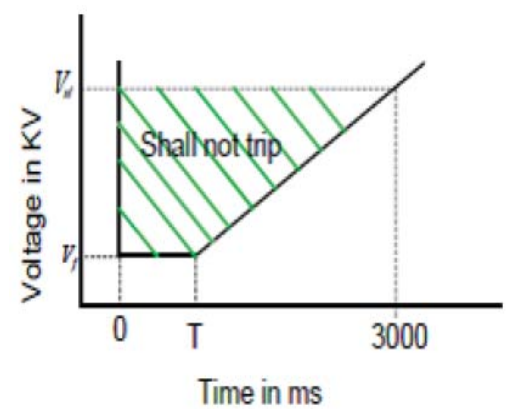

Figure 1. LVRT of Wind farm as per IEGC

Section 3 proposes the Proposed Decoupled Voltage Oriented controller strategy for DFIG.The Section 4 discusses Simulation results and discussion and Section 5 gives the conclusions.

\section{DFIG Wind Generation System}

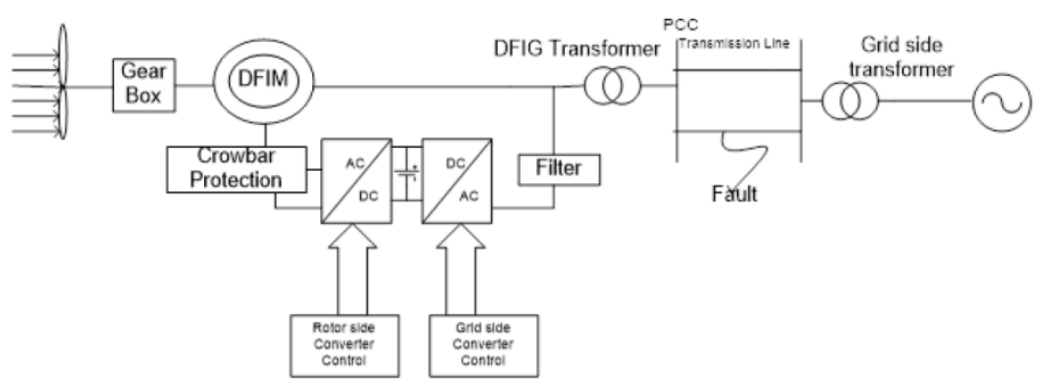

Figure 2. Schematic diagram of Grid Connected DFIG

The Schematic diagram of Grid Connected DFIG is shown in Figure 2. DFIG stator is directly connected to utility grid through step up transformer and rotor side is connected to grid via two back to back Converters. The variable speed operation of DFIG is possible through Power electronic converter. The rating of the frequency converter is usually one third of the total generator rating. The reduced rated converter is more economical than other type of Wind generators. The two converters are connected by large DC Link Capacitor. In Subsyncronous mode of operation Rotor Side Converter (RSC) acts as Inverter and GSC acts as Rectifier and the active Power flows from Grid to DFIG and in Supersychronous mode of Operation RSC acts as Rectifier and GSC acts as Inverter and the active Power flows from DFIG to Grid. The main 
Purpose of GSC is to maintain DC Link Voltage Constant and ensures Unity Power factor at the Grid side terminals and provides additional reactive Power support during abnormal conditions and maintains Voltage at the Wind farm terminals Constant.The Purpose of RSC is to control the stator active and reactive Power independently by controlling $\mathrm{dq}$ components of rotor currents. DFIG is very sensitive to grid disturbance since stator is directly connected to grid, during normal conditions the stator airgap flux is constant but in abnormal conditions under severe voltage dips in the grid side, the stator voltage changes abruptly but the air gap flux cannot change instantly according to constant flux linkage theorem. So a large transient flux with dc component is induced in the stator which in turn induces large rotor flux and rotor emf in the rotor circuit. The large induced emf in the rotor causes large rotor current and may damage the converter. The output voltage of the converter may exceed and RSC control is lost. The DFIG acts like a conventional squirrel cage induction generator when rotor side converter control is lost during severe voltage dip conditions. The Conventional induction generator draws more reactive Power from the grid and voltage at the Wind farm terminals still decreases. Due to loss of control of RSC during fault condition the rotor power cannot be transferred to the grid side.So the excess amount of energy is stored in dc link which causes the dc link voltage to rise suddenly. So a novel Control strategy of Decoupled Feed Forward Voltage Oriented Current control strategy is implemented for Grid side Converter of DFIG to control the DC Link Voltage and Voltage at the Wind farm terminals and at PCC.During fault period, grid side Converter acts as STATCOM by controlling reactive Power to and from the grid and maintains Voltage at Wind farm terminals and PCC is Constant. In the next section the mathematical modeling of grid side Converter and proposed Control strategy for GSC is discussed.

\section{Mathematical Modeling of Grid Side Converter of DFIG}

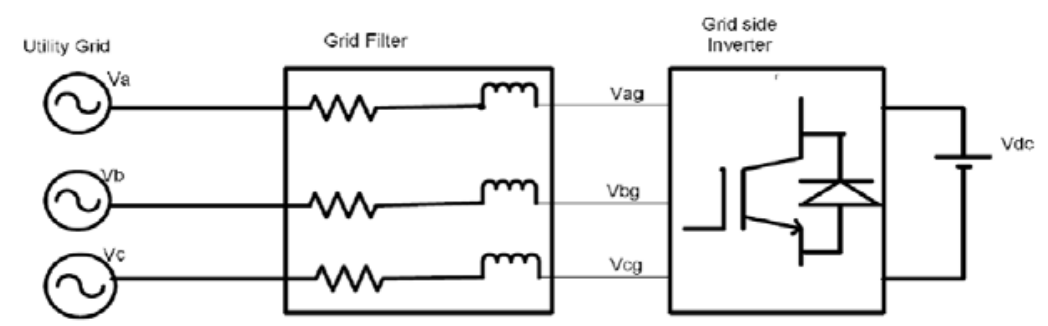

Figure 3. Grid connected Grid side Converter

Figure 3 Shows the Mathematical Model of utility Source Connected to grid side inverter. In the Figure $3, \mathrm{Va}, \mathrm{Vb}, \mathrm{Vc}$ are the utility grid Voltage and $\mathrm{Vag}, \mathrm{Vbg}, \mathrm{Vcg}$ are the voltages at the grid Side Inverter. $L$ and $R$ are the leakage reactance and Resistance of filter between utility grid and Inverter terminal. The voltage equations from KVL can be written as shown below.

$$
\begin{aligned}
& V_{a}=i_{a g} R_{g}+L \frac{d i_{a g}}{d t}+V_{a g} \\
& V_{b}=i_{b g} R_{g}+L \frac{d i_{b g}}{d t}+V_{b g} \\
& V_{c}=i_{c g} R_{g}+L \frac{d i_{c g}}{d t}+V_{c g}
\end{aligned}
$$

The synchronous dq voltage equations can be obtained in grid voltage reference frame with $d$-axis aligning with grid voltage. The Voltage equations in dq synchronous reference frame given by: 


$$
\begin{aligned}
& V_{d}=i_{d g} R_{g}+L \frac{d i_{d g}}{d t}-W L_{g} i_{q g}+V_{d g} \\
& V_{q}=i_{d g} R_{g}+L_{g} \frac{d i_{q g}}{d t}-W L_{g} i_{d g}+V_{q g}
\end{aligned}
$$

$W$ is the angular speed of the rotating reference frame $L$ is the total inductance per phase. If Resistance $R$ is neglected and $q$ axis current is set at zero under normal conditions to maintain unity Power factor at grid side converter. Then the above equations will become:

$$
\begin{aligned}
& V_{d}=i_{d g} R_{g}+L_{g} \frac{d i_{d g}}{d t}-W L_{g} i_{q g}+V_{d g} \\
& 0=L_{g} \frac{d i_{q g}}{d t}-W L_{g} i_{d g}+V_{q g}
\end{aligned}
$$

The dq voltage equation a shown in above equations in grid connected VSI are not completely dependent due to cross coupling terms $W L i_{d}$ and $W L i_{q}$ involved as given in Equations (4) and (5). The Influence of q-axis on d-axis and the effect of d-axis on q-axis deteriorate the performance of the controller. For independent control of $d$ and $q$ axis Currents these cross coupling terms are compensated by grid feed forward terms as shown in Figure 4. The power balance equations are:

$$
P=\frac{3}{2}\left(V_{d} I_{d}+V_{q} I_{q}\right)
$$

Since the d-axis rotating reference is aligned with Grid Voltage Vector We can set $\mathrm{Vq}=0$. With this the Power Balance Equation becomes:

$$
\begin{aligned}
& P=\frac{3}{2}\left(V_{d} I_{d}\right) \\
& Q=\frac{3}{2}\left(V_{q} I_{q}\right)
\end{aligned}
$$

This decoupling makes real and reactive Power to control independently by controlling the $d$-axis and q-axis Currents

\section{Proposed Decoupled Feed Forward Voltage Oriented Current Controller for DFIG Grid Side Converter}

The Proposed Decoupled feed forward Voltage Oriented current Controller is shown in Figure 4. The main objective of Proposed Controller is to control the active Power, reactive Power, DC Link Voltage and Voltage at PCC during Voltage dip Conditions. For better Dynamic performance and accuracy of Voltage Oriented controller, a decoupled controller is incorporated at PI Controller output by adding Grid voltage feed forward terms in order tonullify the effect of cross coupling effect of $d$ axis on $q$-axis component vice versa. The Voltage Oriented control scheme uses dq rotating reference frame to transform the grid voltage and current variables to $\mathrm{dc}$ variables. In this control $\mathrm{d}$-axis is aligned along grid voltage vector so current in $\mathrm{d}$-axis generates active power and current along the qaxis controls the reactive power.In this control structure PI controllers are usually used, as it provides zero steady state error when controlling DC magnitudes. In proposed strategy inner loop controls the grid current to ensure balanced and quality current into the grid network. The outer loop regulates the reactive power delivered to grid and DC link voltage. The controller objective is to maintain DC link voltage constant so that active power is completely transferred to the grid and improves power factor to be at unity 
at the converter terminals. In this control Strategy Conventional PLL is used to extract grid phase angle for dq transformations.

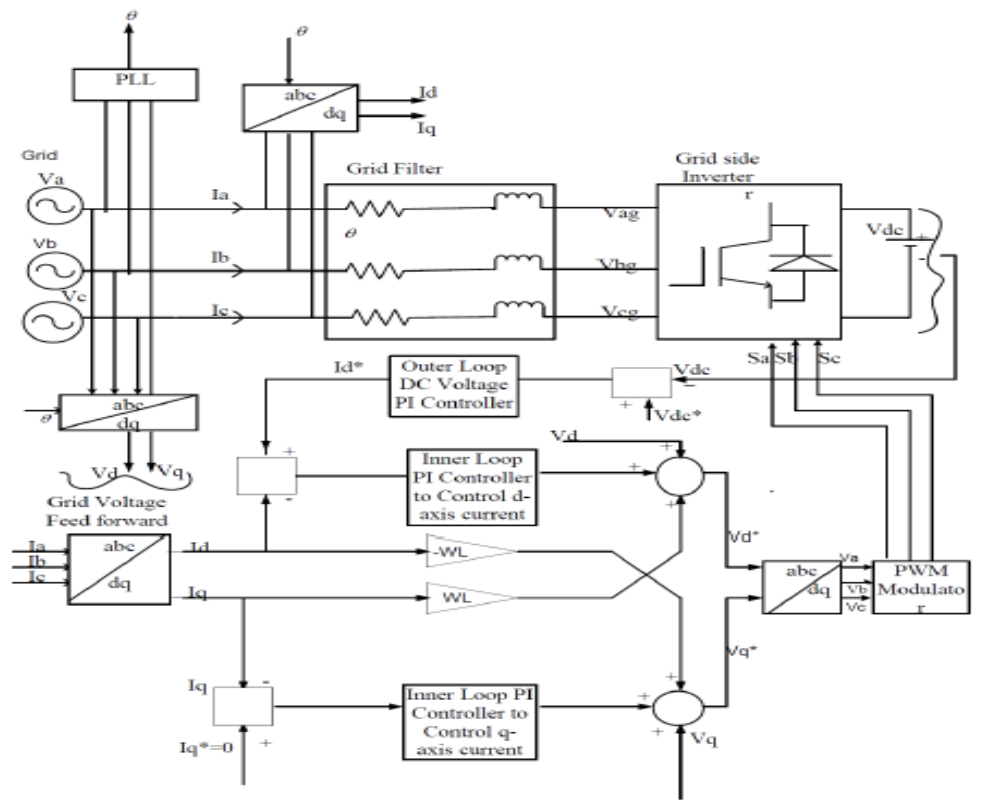

Figure 4. Proposed Decoupled Feed forward Voltage Oriented Current Controller

\section{Simulation Results and Discussion}

Case 1: Balanced Fault Condition

A balanced voltage sag of $50 \%$ is applied at $\mathrm{t}=0.06 \mathrm{Sec}$ in grid network as shown in Figure 5. Due to voltage sag in the grid network the voltage at the wind farm slightly reduces to 0.9 Per unit during the faulty period from $0.06 \mathrm{sec}$ to 0.1 Seconds and then finally settle down to prefault wind farm voltage of 1 per unit as shown in Figure 6 . Due to reduction in the stator voltage at the terminals of DFIG the stator current may suddenly rises to large value with no proper control which results in large increase in rotor current causing the converter to trip. Here the proposed controller can effectively control the current injected into grid and helps the DFIG to ride through even under large balanced voltage sags in grid network. The current in the DFIG shoots up to 1.1 per unit during sag Period and finally settles down to 1 per unit as shown in Figure 7 and Figure 8. Due to voltage sag in grid network, the increase in current raises the DC Link voltage of converter increases as shown in Figure 9 and causes severe damage to converter and trip the DFIG from the network. The DC Link voltage set at reference voltage of 1150 in the converter which is to be maintained at all normal and abnormal conditions. The proposed controller effectively controls dc link voltage which oscillates around reference set value and finally settles to safe value of $1180 \mathrm{~V}$ which helps the wind generator to avoid tripping under voltage dip condition. The active power slightly reduces from 9MW to 8MW during sag condition as shown in Figure 10 and after the sag is restored at $t=0.1$ Sec the active power continues to generate $9 \mathrm{MW}$ to the grid network. In this case the proposed controller helps the uninterrupted and reliable power supply to network even under abnormal conditions. At the GSC the reactive power is 0 MVAR under normal conditions. The reactive power generated by grid converter increases to 1.5MVAR during the abnormal condition for voltage support at the DFIG terminals and after $t=0.1 \mathrm{sec}$ the reactive power finally settles to OMVAR as shown in Figure 11. 


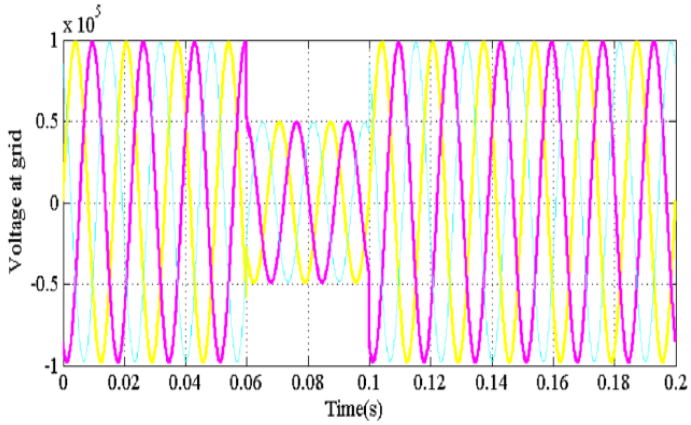

Figure 5. Voltage at the Grid Terminals under balanced sag condition

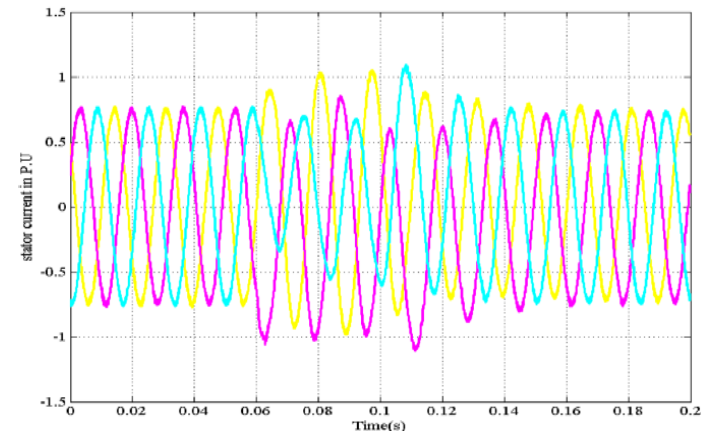

Figure 7. Stator Current under balanced sag condition

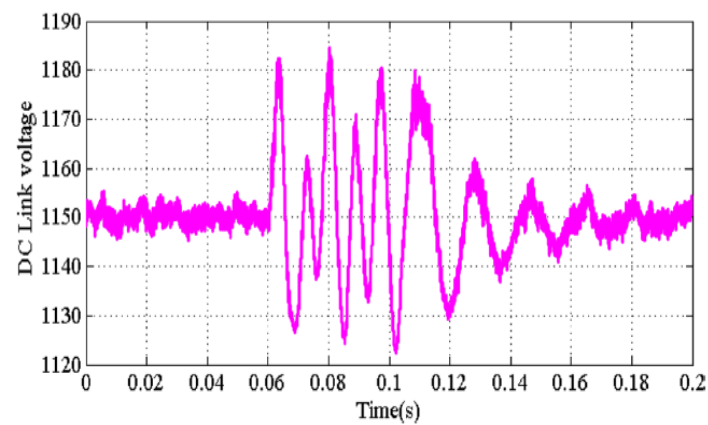

Figure 9. DC Link Voltage under balanced sag condition

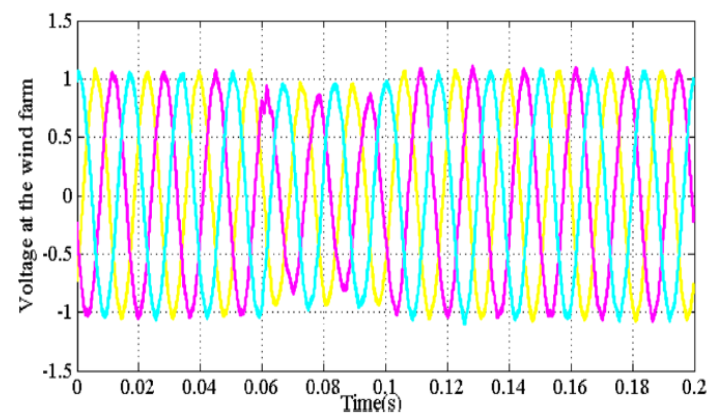

Figure 6. Voltage at Wind farm terminal under balanced sag condition

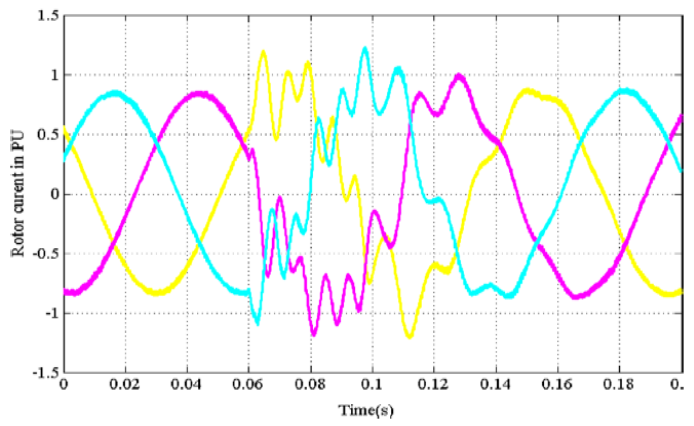

Figure 8. Rotor Current under balanced sag condition

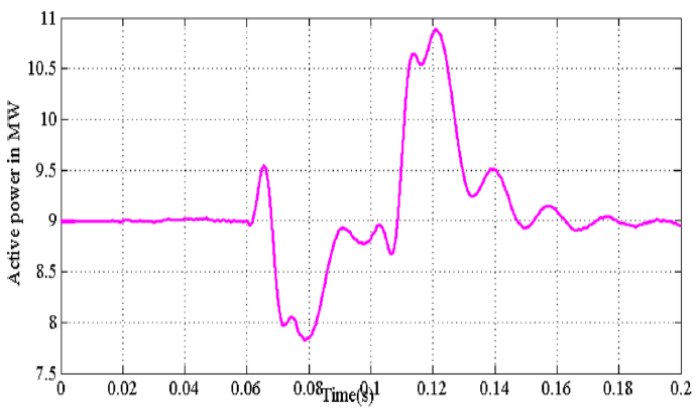

Figure 10. Active power under balanced sag condition

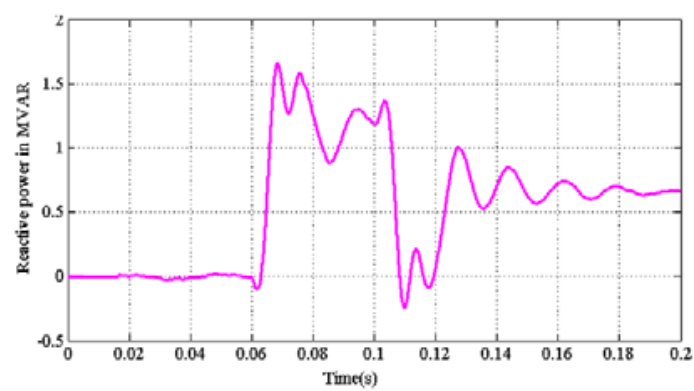

Figure 11. Reactive power under balanced sag condition

TELKOMNIKA Vol. 15, No. 2, August 2015 : $209-216$ 
Case 2: Unbalanced single line to ground Fault

Due to remote grid faults, voltage dip appear at the different buses of the power System and results in adverse effect on the operation of Wind farm. When single line to ground fault takes place at remote grid at time $\mathrm{t}=0.06$ seconds and lasts for $400 \mathrm{~ms}$, the voltage at wind farm drops down to $80 \%$ of normal value as shown in Figure 12 and maintains at rated value after the fault is cleared. Figure 13 shows under normal conditions reactive power is set at 0 Mvar and during faulty conditions little amount of reactive power is supplied by GSC to support the voltage at the wind farm terminals. In this way the proposed control strategy supports voltage at the DFIG terminals constant by controlling the reactive power transaction between the grid and wind turbine. When one of the phases gets effected due single line to ground fault at PCC the current in unhealthy phase increases to abnormal value as shown in Figure 14 and trips the DFIG. But the Proposed current controller limits the current to reach to abnormal value and helps wind turbine to stay connected to grid even under faulty condition. When single Line ground fault happens to occur at $\mathrm{t}=0.06$ Seconds Dc Link Voltage suddenly Jumps to large value shown in Figure 15 and comes to normal value after the fault is vanished. During the faulty period the dc link voltage oscillates and come down to set value. The Proposed controller suppresses the dc link voltage to large value and avoids the DFIG to trip from grid.

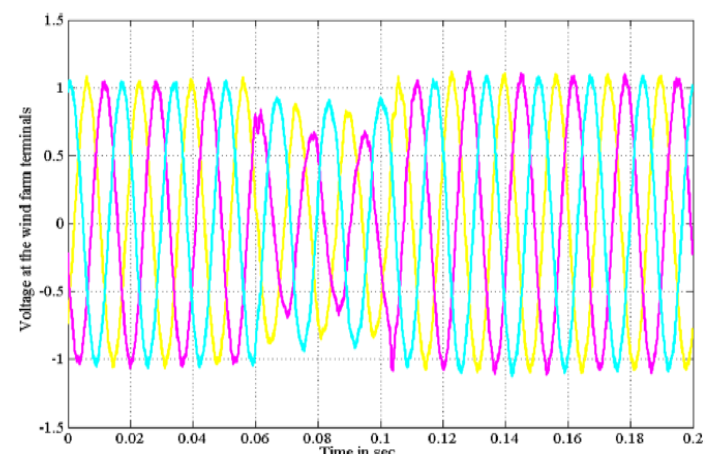

Figure 12. Voltage at the Wind farm With LG Fault

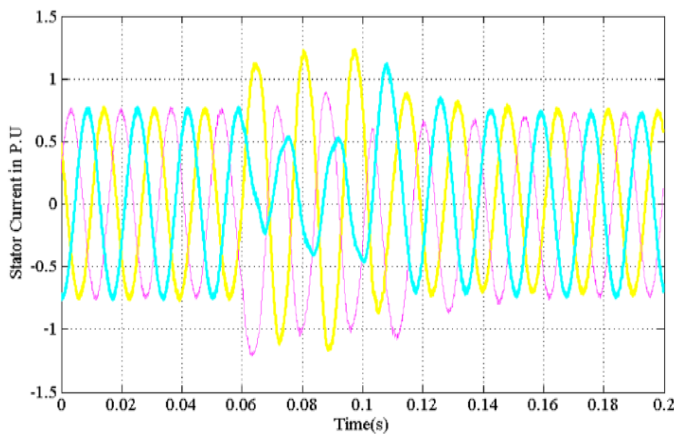

Figure 14. Stator current at Wind farm Under LG Fault

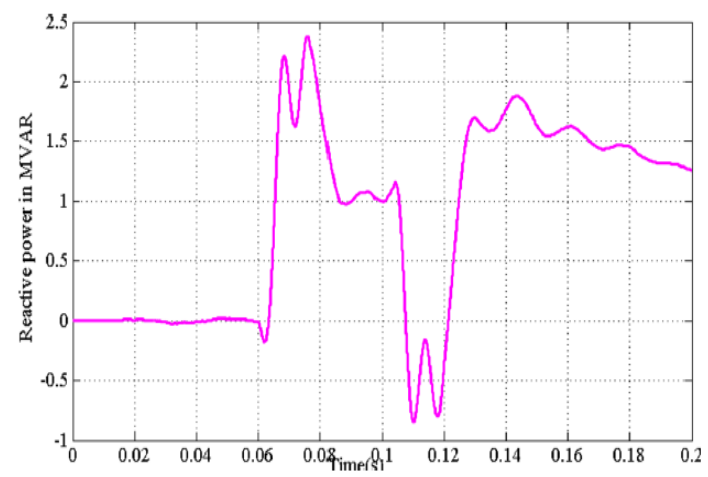

Figure 13. Reactive Power delivered by Grid side converter With LG Fault

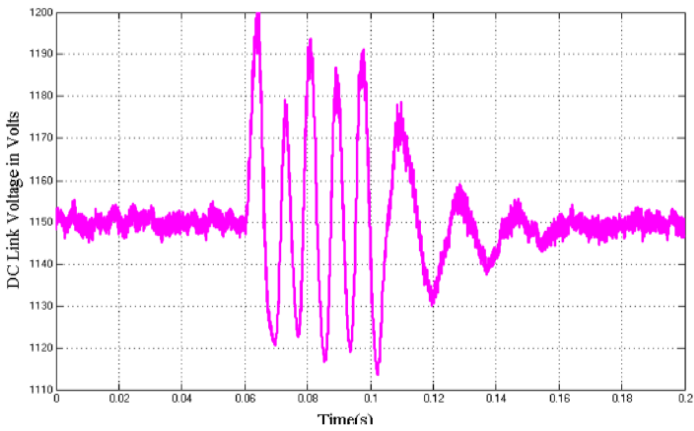

Figure 15. DC link voltage with LG Fault

\section{Conclusion}

This paper has presented a Control Scheme for DFIG to enhance the Performance of DFIG under balanced and unbalanced fault Conditions. The proposed Controller was implemented in Stator Voltage Oriented reference frame for Grid side Converter. The proposed controller effectively mitigates DC Link Voltage, Stator Current, Rotor Current and Voltage at Wind Farm terminals under abnormal Conditions. The Simulation results have been presented 
to show the effectiveness of the Proposed Controller.From the results it is shown that the proposed control scheme for DFIG results in less Oscillations in DC Link Voltage, Stator/rotor Currents and stator active and reactive power during the faulty period and all the paramaters of DFIG lying within the safe limits without damaging the converter which helps the DFIG to remain in service to generate the active and reactive Power to grid continuously even under grid disturbance conditions. From the results it was shown that grid code requirements set by grid code operators have been fulfilled and allows the Wind turbine to stay in service under grid contingencies.

\section{References}

[1] Hua Geng, Cong Liu, Geng Yang. LVRT Capability of DFIG-Based WECS under Asymmetrical Grid Fault Condition. Industrial Electronics, IEEE Transactions. 2013; 60(6): 2495-2509.

[2] Dongliang Xie, Zhao Xu, Lihui Yang, Ostergaard J, Yusheng Xue, Kit Po Wong. A Comprehensive LVRT Control Strategy for DFIG Wind Turbines With Enhanced Reactive Power Support. IEEE Transactions Power Systems. 2013; 28(3): 3302-3310.

[3] J Matevosyan, T Ackermann, S Bolik, L SdeR. Comparison of International regulations for connection of wind turbines to the network. In Proc. NWPC. Gothenburg, Sweden. 2004; 1: 1-7.

[4] Qiao, RG Harley. Grid connection requirements and solutions for DFIG wind turbines. In Proc. IEEE Energy 2030 Conf. Atlanta, GA, USA. 2008: 18.

[5] Central Electricity Regulatory Commission, Ministry of Power, Central Government of India, Indian Electricity Grid Code. New Delhi, India: Central Electricity Regulatory Commission. 2010.

[6] J Lopez, P Sanchis, X Roboam, L Marroyo. Dynamic behavior of the doubly fed induction generator during three-phase voltage dips IEEE Trans. Energy Conversation. 2007; 22(3): 709-717.

[7] J Morren, SWH de Hann. Ride through of wind turbines with doubly-fed induction generator during a voltage dip IEEE Trans. Energy Conversion. 2005; 20(2): 435-441.

[8] I Erlich, H Wrede, C Feltes. Dynamic behavior of DFIG-based wind turbines during grid faults. In Proc. Power Converters. Conf. Nagoya, Japan. 2007: 1195-1200.

[9] Chi Jin, Peng Wang. Enhancement of low voltage ride-through capability for wind turbine driven DFIG with active crowbar and battery energy storage system. Power and Energy Society General Meeting. 2010; 1(8): 25-29.

[10] I Erlich, J Kretschmann, J Fortmann, S Mueller-Engelhard, H Wrede. Modeling of wind turbines based on doubly-fed induction generators for power system stability studies. IEEE Trans. Power Systems. 2007; 22(3): 909-919.

[11] J Yang, JE Fletcher, J OReilly. A series dynamic resistor based converter protection scheme for doubly-fed induction generator during various fault conditions. IEEE Trans. Energy Conversion. 2010; 25(2): 422-432.

[12] AH Kasem, EF El-Saadany, HH El-Tamaly, MAA Wahab. An improved fault ride-through strategy for doubly fed induction generator-based wind turbines. IET Renew Power Gen. 2008; 2(4): 201-214.

[13] S Foster, L Xu, B Fox. Coordinated reactive power control for facilitating fault ride through of doubly fed induction generator and fixed speed induction generator-based wind farms. IET Renew Power Gen. 2008; 4(2): 128-138. 